\title{
COGNITIVE MAPPING IN SPACES FOR PUBLIC USE
}

\author{
Rishab Chopra ${ }^{1}$, Gaurab Das Mahapatra ${ }^{2}$ \\ ${ }^{1}$ UG B.Arch. Student, School of Architecture, GITAM (deemed to be) University Visakhapatnam Campus, A.P., India \\ ${ }^{2}$ Assistant Professor, School of Architecture, GITAM (deemed to be) University Visakhapatnam Campus, A.P., India
}

\begin{abstract}
Cognitive mapping might be considered as an essential element of pre design/ post design phase for public spaces. Cognitive maps can be defined as a category of mental representation and concepts that are built to visualize and obtain information. The reason why people use cognitive mapping is to create an opportunity to represent their experiences about their environment. Public spaces provide a space in which people can come in contact with the social world outside and experience the opportunity of being with, seeing and hearing others which instills stimulation. This paper aims towards the role of cognitive mapping in spaces for public use. Besides, the relevance and impact of Cognitive Mapping in Public spaces is also discussed. The five principles of Kevin Lynch i.e. paths, nodes, districts, edges and landmarks are considered for understanding the impact of cognitive mapping in spaces for public use. Thereafter, the Influence of Cognitive Mapping in determining success / failure of a Public Spaces is also looked upon. Next, two cases of Mexico City and Melbourne, involving cognitive mapping in places for public use is mentioned to understand the practical implications of the topic. Lastly, observations from primary survey/exercise for understanding cognitive mapping in spaces for public use undertaken by the authors have been mentioned. These primary studies had been done in Jodhpur, Chandigarh and Visakhapatnam. The inferences and facts from the paper might be used by architects and planners to understand the considerations to be taken before starting to visualize a successful public place.
\end{abstract}

Keywords: Cognitive Mapping, Public Spaces, Architects, Planners

\section{INTRODUCTION}

Cognitive Mapping: Cognitive maps can be defined as a category of mental representation and concepts that are built to visualize and obtain information. Cognitive mapping might be referred to as a frame of reference, schematics, mind maps and mental maps. They act as a tool for strategists to move beyond the constraints of short term memory and to process information spanning long periods of time [1]. It simplifies knowledge, upsurges memory and improves cognition.

Public Spaces: Public spaces give people- a chance to feel differently, see something new, to learn and to be inspired. A public space can be perceived as not only a place but also an experience. Public spaces play an important role in the social development of people in many levels; from miniature neighbourhood to large city centre squares [2]. Public spaces are places of great value where people of different background come together and pick up new notions

Relevance of Cognitive Mapping in Public Spaces: Cognitive mapping are the mental representation of the worlds in which we live. They are built of our individual experiences and recorded as memories. Cognitive mapping estimate how people define their own perceptions and experience which influence them to decide and keep living in particular places. The reason why people use cognitive mapping is to create a prospect to characterize their experiences about their environment and how they decipher their problems [3].

\section{PUBLIC SPACES}

An ideal public space should allure people to slow down (in terms of visual experience) and subtly experience the place. It should not be just used as a transitional space to pass by; rather, it should be a place that improves the lives of the people using it. This entirely depends upon the design of public spaces in terms of diversity, comfort, safety, accessibility, aesthetics etc. [4]. Aspects like nature of space usage, organization of street furniture, spacing of street lights, landscape design, paving pattern, material finishes and activities zones play a major role in determining the level of success for public spaces, e.g. Fig-1 and Fig-2.

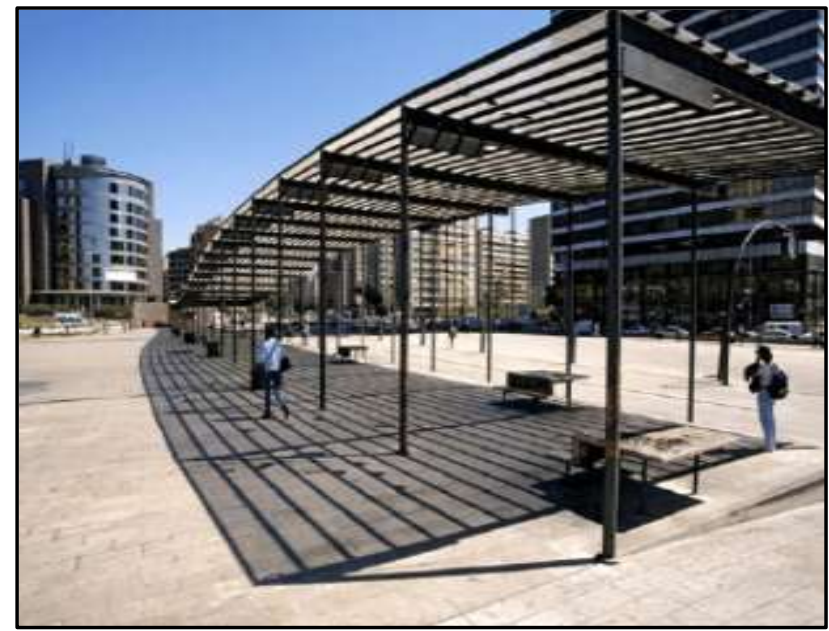

Fig -1: Placa Dels Paisos Catalans, Barcelona 


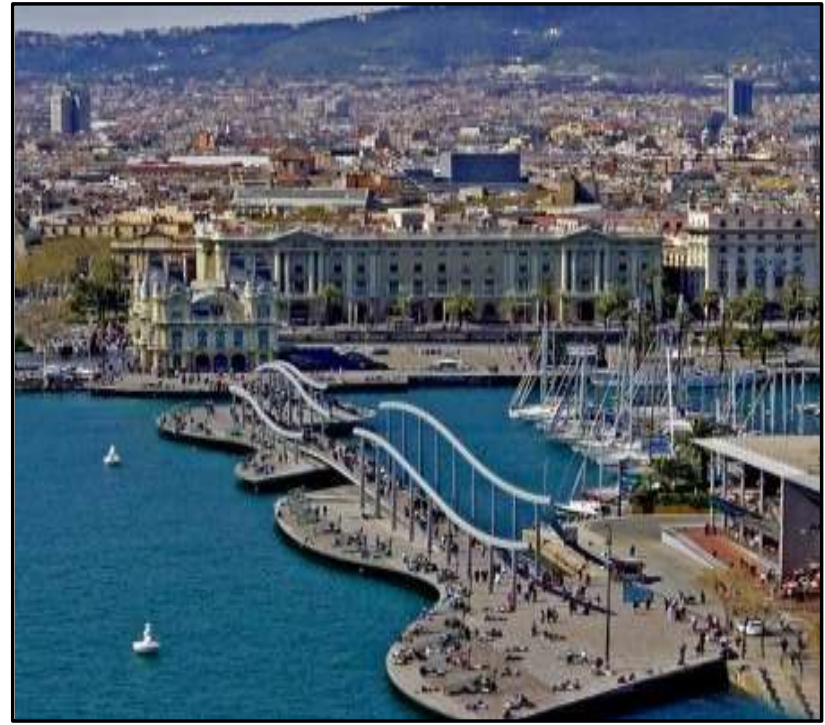

Fig -2: La Rambla Del Mar, Barcelona

\subsection{Impact of Cognitive Mapping in Public Spaces}

Generically, cognitive mapping is used to reveal the emotional and physical relationship that individuals make with the spaces in their respective domain. Cognitive mapping in public spaces can be observed by using five basic elements of renowned Urban Designer Prof. Kevin Lynch. The five basic elements are: paths, nodes, districts, edges, landmarks [5].

- Paths can be defined as connective network (such as pavements, streets etc).

- Edges acts as a boundary (such as forests, rivers etc).

- Districts are the areas where inhabitants shape their physical boundaries in their minds.

- Nodes are the strategic point of the city where intersections occur.

- Landmarks are structures that attract attention of the inhabitants.

A particular example of a study involving Lynch's five elements and cognitive mapping might be of relevance for this paper. The study was conducted in Eskisehir Osmangazi University Meselik Campus, where first year Architecture students were requested to draw the cognitive mapping of campus using Lynch's principal to determine how the imaginary elements of the campus are positioned in their memories.

According to research findings, it was observed that students first perceived paths and landmarks and then edges, districts and nodes which do not necessarily coincide with Lynch's argument. Lynch expresses that districts and then path will be emphasized first in urban perception. The reason for encountering a different outcome than Lynch could be that students have faced more with the buildings and subsequently have found these structures more noticeable than other building in the settlement.

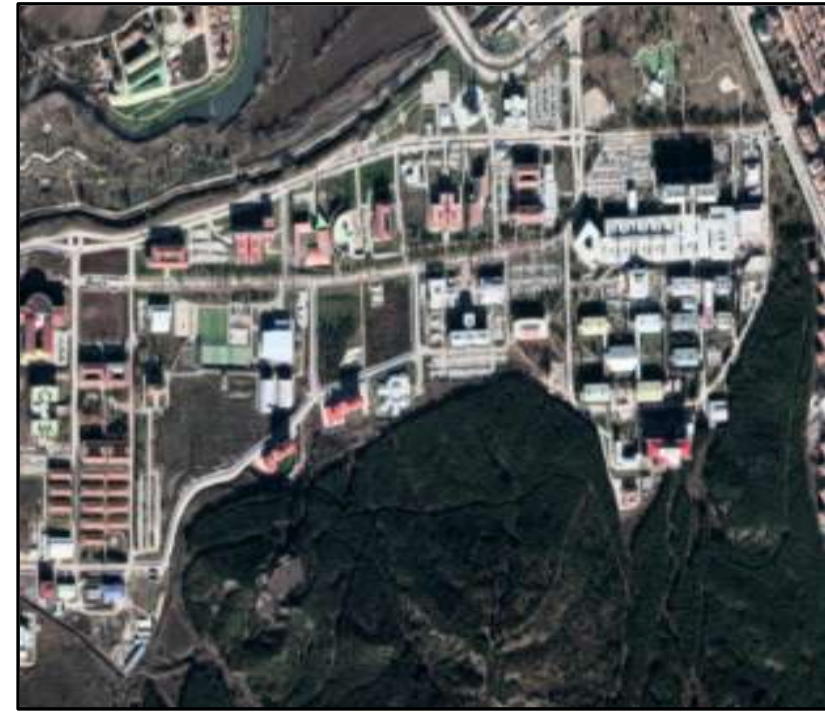

Fig -3: General spatial order of Eskisehir Osmangazi University Meselik Campus Area.

\subsection{Influence of Cognitive Mapping in Public}

\section{Spaces for both Visually Impaired and Able Bodied}

Cognitive mapping of spaces and of the possible path for navigation spaces is imperative for the development of efficient orientation and mobility skills. Information required for the cognitive mapping is gathered through the visual channel of its user interface. People who are visually impaired lack this information, and are consequently required to use sensorial channels and alternative exploration methods [6]. The supply of appropriate spatial information through sensorial channels may help to enhance the ability to explore unknown environments and to navigate in real environments for people with visual impairment.

\section{RELEVANT EXAMPLES OF COGNITIVE MAPPING IN PUBLIC SPACE}

In this section, the influence of cognitive mapping in determining success / failure of public spaces is also viewed upon. Two cases of Mexico City and Melbourne, involving cognitive mapping in places for public use is elaborated to understand the practical implications of the topic.

\subsection{Cognitive Mapping of City Square, Melbourne}

City square, a plaza is the main civic centre and public space for the city of Melbourne. The surroundings of the square cover the city's central street networks, which are Swanston Street and Collins Street. Its immediate surrounding is the Westin Hotel, the iconic and historic St. Paul's Cathedral, the Regent Theatre, Melbourne Town Hall and the Paul's Cathedral. There is a tramway stop in front of the square, which is dynamically used by people to walk to the adjoining streets, lane ways and buildings. Three architecture graduates designed the spaces and components of the square that consisted of a video screen, restaurants, a basement arcade shops and outdoor cafes (Fig -4). These 
spaces were connected by sunken amphitheater, glazed canopy, reflecting pool, graffiti wall, cascades and water wall [7].

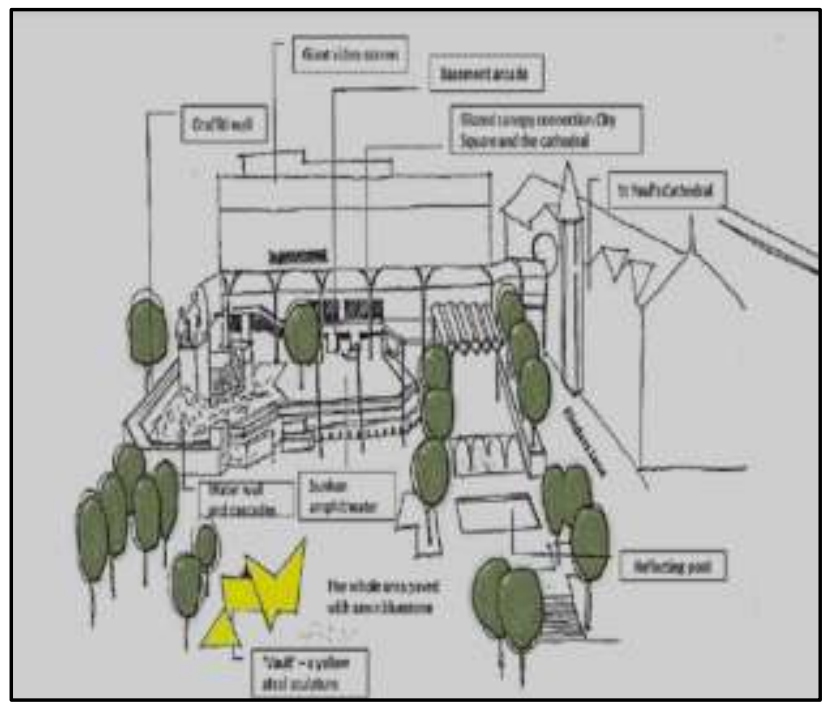

Fig -4: Cognitive mapping of City Square, Melbourne

\subsection{Cognitive Mapping of Mexico City}

Fig-5 shows the iconic building and important avenues of Mexico City. The city is surrounded by mountains and used to be a city on water with lakes and canals everywhere before Spain conquered this territory and dried it all [8].

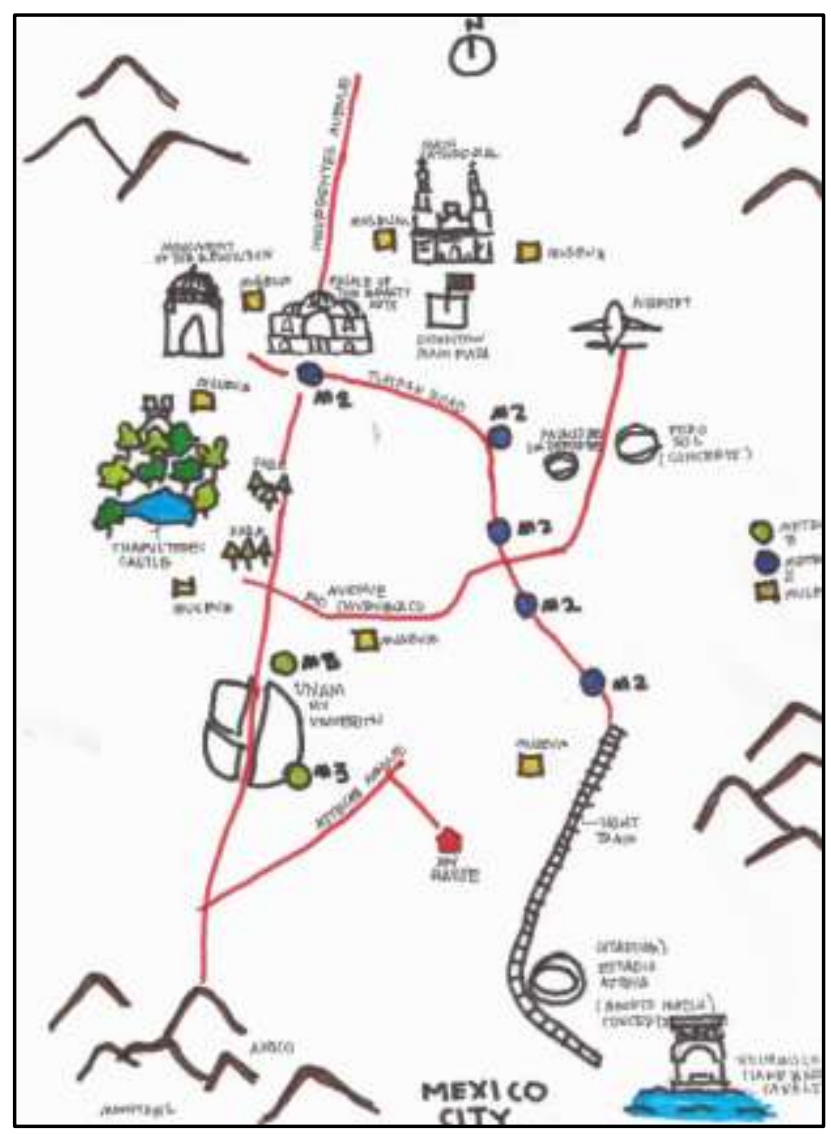

Fig -5: Cognitive mapping of Mexico City

\section{PRIMARY STUDY FOR COGNITIVE} MAPPING IN SPACES FOR PUBLIC USE

Observations from primary survey/exercise for understanding cognitive mapping in spaces for public use were undertaken by the authors.

These primary studies had been done in Jodhpur, Chandigarh and Visakhapatnam.

\subsection{Jodhpur: Old City Core}

Historic city core of Jodhpur comprises of the fabric of narrow streets, huddling of blue houses and Havelis on the terrain. The old city has grown around the Tripolia Market, Ghantaghar, Mehrangarh Fort, Ranisar Lake, Chand pole and Jaswant Thada. As per urban legends, Jodhpur is also known as the Blue city; because most of the houses in the old city are painted in shades of blue particularly noticeable on the north side of town.

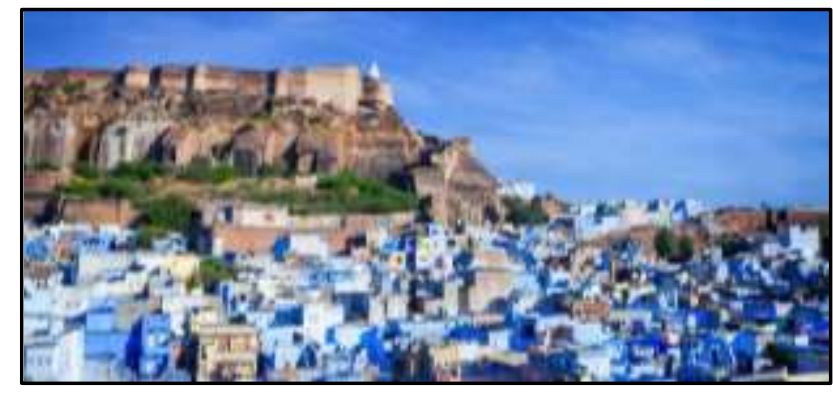

Fig -6: Jodhpur - the blue city

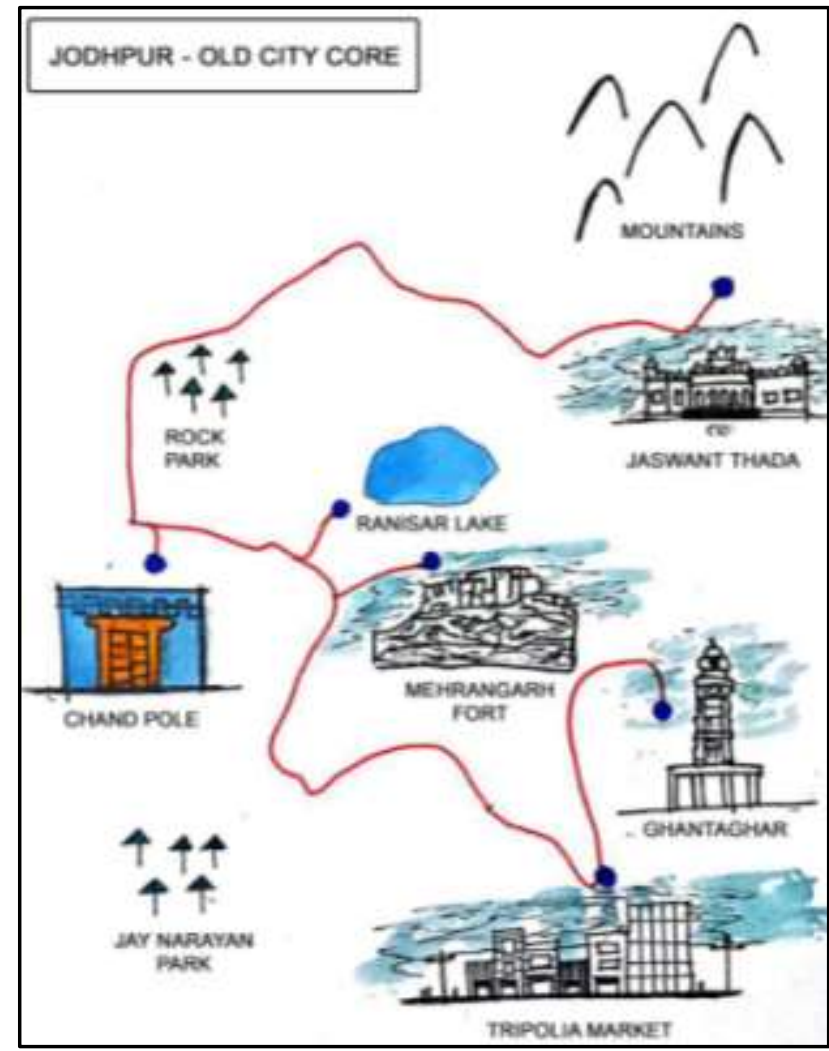

Fig -7: Cognitive Map for Jodhpur (Source: Authors) 


\subsection{Chandigarh: Capitol Complex}

The master plan of Chandigarh city was prepared by Architect Le Corbusier. Most of the government building and housing in the city were designed by Le Corbusier. In July 2016 Chandigarh capitol complex declared as World Heritage by UNESCO. The capitol complex buildings include the Punjab and Haryana High Court, Secretariat, Legislative Assembly along with monuments Open hand, Martyrs Memorial and Tower of Shadow.

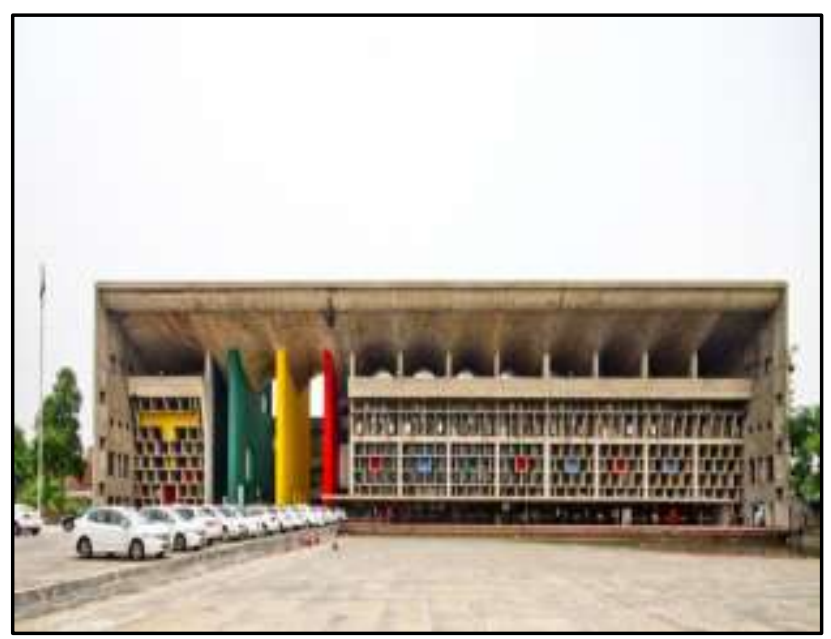

Fig -8: Chandigarh High Court

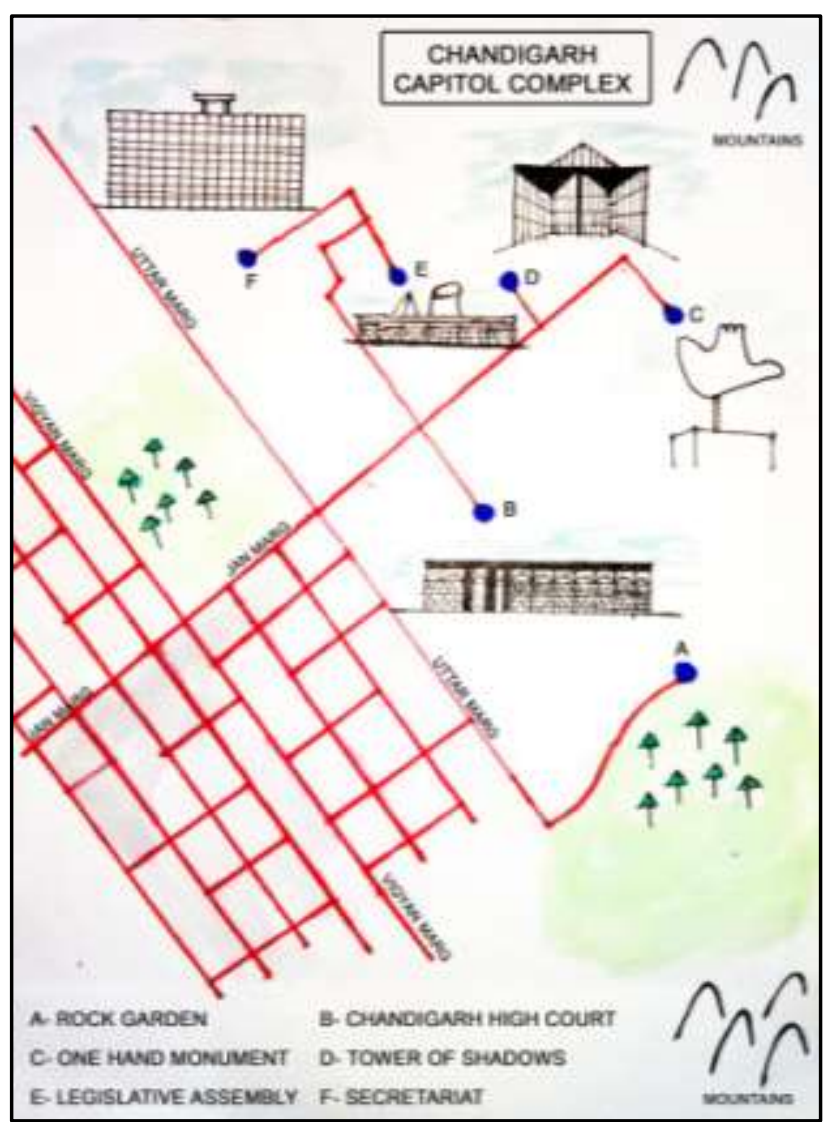

Fig -9: Cognitive Map for Chandigarh capitol complex (Source: Authors)

\subsection{Visakhapatnam: Jagdamba Complex}

Jagadamba centre acquire its name after the famous Jagadamba Theatre at this central junction of the city of Visakhapatnam. This centre forms the good old central shopping, entertainment, government building and health hub of this port city.

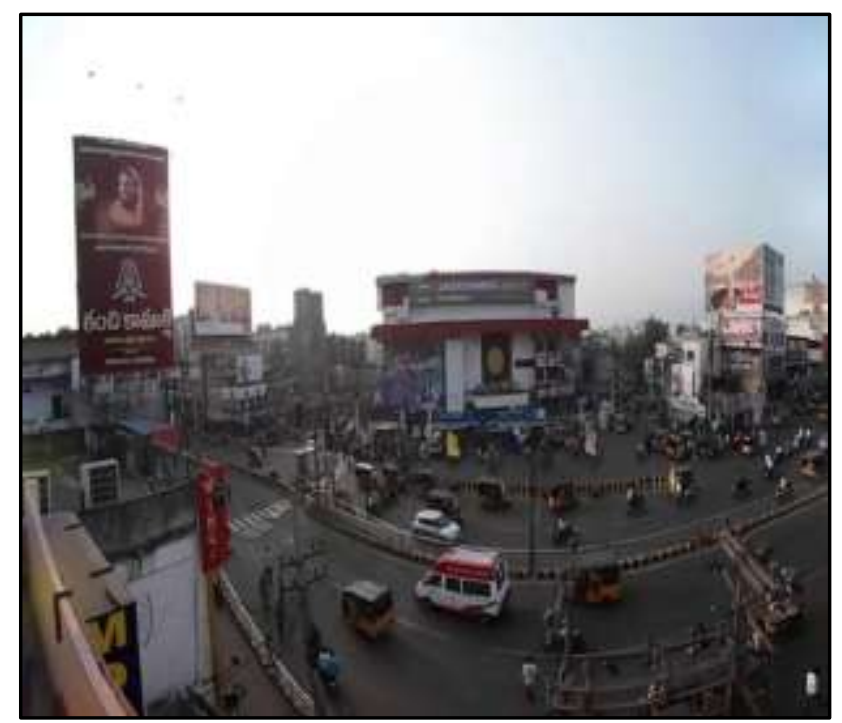

Fig -10: Panaromic view of Jagadamba junction

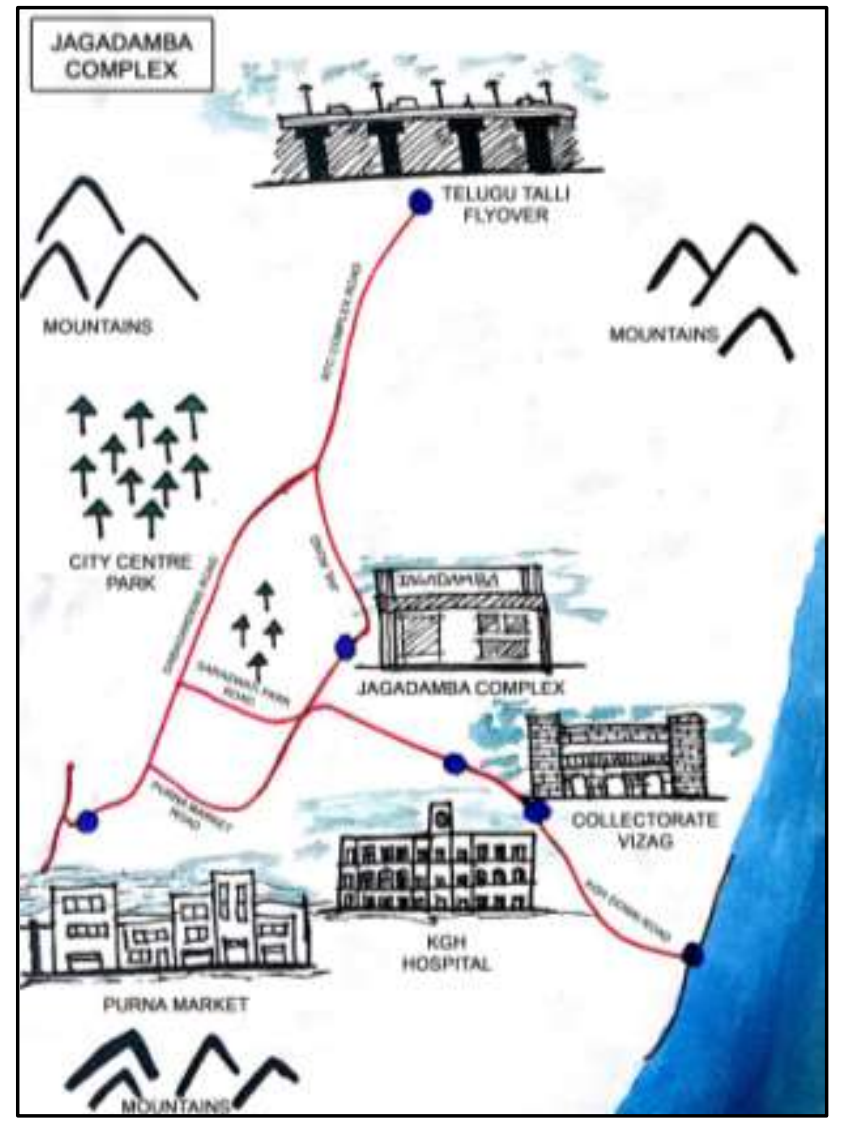

Fig -11: Jagadamba Complex, Visakhapatnam (Source: Authors) 


\section{CONCLUSION}

In the cases of Jodhpur and Visakhapatnam, the major elements which constitute the cognitive map are the places which have been eminent during the evolution of the city and serves as a historic dimension to the city fabric. In case of Chandigarh, the element with eminent architectural and functional significance forms the constituents of the cognitive map.

Thus, the inferences and facts from the paper might be used by architects and planners to understand the considerations to be taken before starting to visualize a successful public place. However, the success of cognitive mapping shall lie in the involuntary association of the users with the space. The placement of blocks, relevance of the structure, relevant degree of usage, user interface and natural elements shall determine the major elements of cognitive mapping.

\section{ACKNOWLEDGEMENT}

This paper would not have been complete with the support of Prof. Dr. K. Mohan, Director, Gitam School of Architecture, GITAM (deemed to be) University; who always inspires us to strive towards personal and academic excellence.

\section{REFERENCES}

[1] Sammut-Bonnici, Tanya. (2015). Cognitive maps. https://www.researchgate.net.

[2] Zakariya, K. (2014). Spatial Characteristics of Urban Square and Sociability: A Review of the City Square, Melbourne. malaysia: https://www.researchgate.net.

[3] Sihombing, A. (2014). Drawing Kampung through Cognitive Maps Case Study: Jakarta. indonesia: research gate.net.

[4] Rupa, C. k. (2015). Importance of public spaces in cities. research gate .

[5] Alptekin, O. (2017 ). A Reading Attempt of the Urban Memory of Eskisehir Osmangazi University Meselik Campus via Cognitive Mapping. http://iopscience.iop.org.

[6] Mioduser, D. Haptic-feedback support for the cognitive mapping of unknown spaces by people who are blind. semanticscholar.

[7] Mansor, M. (2014). Spatial Characteristics of Urban Square and Sociability: A Review of the City Square, Melbourne. Malaysia: research gate.

[8] Laura, A. cognitive mapping of Mexico City. Mexico.

\section{BIOGRAPHIES}

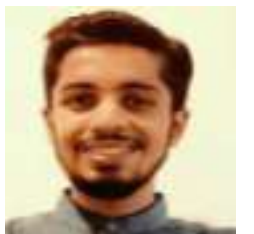

Mr. Rishabh Chopra is an undergraduate B.Arch. Student, School of Architecture, GITAM (deemed to be) University. He has been enthusiastic about designing public spaces and cognitive mapping in architecture.

rishabhchopra441@gmail.com +91-7974067835

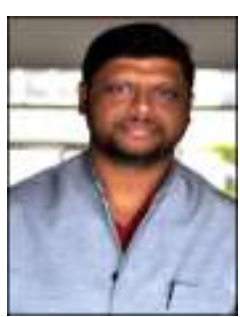

Ar. Gaurab Das Mahapatra is an Assistant Professor in School of architecture, GITAM (deemed to be) University. A double gold medalist in Masters in Urban \& Regional Planning, Ar. Mahapatra has keen interest in designing and analysis of public spaces. $\mathrm{He}$ has international and national publications to his credit. gaurabdasmahapatra@gmail.com +91-9866955757 